\title{
Cerebellar liponeurocytoma - a rare entity: a case report
}

\author{
Oliver Gembruch ${ }^{1 *}$, Andreas Junker $^{2}$, Yahya Ahmadipour $^{1}$, Ulrich Sure $^{1}$ and Elias Lemonas ${ }^{1}$
}

\begin{abstract}
Background: Cerebellar liponeurocytoma is a rare tumor of the central nervous system occurring mainly in the posterior fossa, which shows neuronal and variable astrocytic differentiation with foci of lipomatous differentiation. Liponeurocytoma develops in adult patients and is defined in the World Health Organization classification of 2016 as a rare benign grade II tumor.

Case presentation: A 39-year-old Italian man presented to our department suffering from headache and nausea. Magnetic resonance imaging revealed a right-sided cerebellar lesion showing poor contrast enhancement without an obstructive hydrocephalus. Surgery was indicated and total tumor resection was achieved. He was discharged without any neurological deficits. Histopathological examinations revealed a cerebellar liponeurocytoma. A neurological follow-up examination revealed no neurological deficit directly after surgery and 1 year later. Radiotherapy was recommended at the neurooncological board despite the total removal of the tumor, but our patient refused adjuvant radiotherapy. Magnetic resonance imaging of his neurocranium with and without contrast enhancement 48 hours after surgery and 15 months after surgery showed no residual tumor.

Conclusions: Liponeurocytomas are rare benign tumors occurring in the majority of cases in the cerebellum. The therapy of choice is surgery. Postoperative radiotherapy has to be discussed individually, but seems to be sufficient if complete tumor resection is not achieved or in cases of a tumor recurrence.
\end{abstract}

Keywords: Cerebellar liponeurocytoma, Cerebellar neoplasm, Radiotherapy

\section{Background}

Cerebellar liponeurocytoma is a rare tumor entity mainly located in the posterior cranial fossa and typically developing in adults with a favorable clinical prognosis. It is histologically characterized by lipidized cells found in clusters or scattered between small neoplastic cells. Immunohistochemical staining shows advanced neuronal/ neurocytic differentiation with a low proliferation index.

Liponeurocytoma was first described in 1978 by Bechtel et al. as a mixed mesenchymal and neuroectodermal tumor in a 44-year-old man with a cerebellar lesion [1]. Some previous cases were published as "unusual medulloblastomas in adults," "lipomatous medulloblastomas," "lipidized medulloblastomas," "neurolipocytomas," or "medullocytomas."

\footnotetext{
* Correspondence: oliver.gembruch@uk-essen.de

${ }^{1}$ Department of Neurosurgery, University Hospital Essen, University of

Duisburg-Essen, Hufelandstrasse 55, 45122 Essen, Germany

Full list of author information is available at the end of the article
}

The World Health Organization (WHO) recognized it in the 2000 WHO classification as a cerebellar liponeurocytoma emphasizing its neurocytic differentiation and classified it in the group of neuronal tumors [2]. In the WHO classification of 2016, the tumor was classified as a glioneuronal tumor and was upgraded to grade II due to the results of long-term follow-up studies showing a higher recurrence rate than originally expected [3].

Although findings from computed tomography (CT) and magnetic resonance imaging (MRI), and pathological and immunohistochemical characteristics have been reported in around 70 cases, clinical and pathological diagnosis of liponeurocytoma remained challenging and the characteristics of this tumor entity are still poorly understood.

Accurate differential diagnosis of this rare central nervous system (CNS) tumor from other brain tumors such as medulloblastoma or oligodendroglioma is important to avoid unnecessary aggressive adjuvant therapies.

(C) The Author(s). 2018 Open Access This article is distributed under the terms of the Creative Commons Attribution 4.0 International License (http://creativecommons.org/licenses/by/4.0/), which permits unrestricted use, distribution, and 
This case report presents a rare case of a liponeurocytoma located in the posterior fossa and summarizes the typical radiological and histopathological features of this rare tumor entity. Tumor recurrence, adjuvant therapy, and important differential diagnoses are discussed.

\section{Case presentation}

A 39-year-old Italian man presented to our department suffering from headache and nausea over the past months. CT and MRI revealed an ill-defined, $39 \times 37 \times$ $29 \mathrm{~mm}$ (anterior-posterior $\times$ transverse $\times$ cranial-caudal) tumor. On $\mathrm{CT}$, the lesion presented as slightly hypointense with poor contrast enhancement. On MRI, a hyperintensity on fluid-attenuated inversion recovery (FLAIR) sequence and on T2-weighted imaging was detected. On T1-weighted imaging, the lesion showed a hypointensity. The lesion showed poor contrast enhancement of the right cerebellar hemisphere without an obstructive hydrocephalus on T1-weighted images with contrast enhancement (Fig. 1).

Our patient did not suffer from any other comorbidities; he had not undergone any surgeries. He did not use medication. He had never consumed alcohol, smoked tobacco, or used other drugs. He is married, has two children, and works as a cook in a family owned restaurant. Similar cases were not reported in his family; no relatives had suffered from a tumor in the past. Neurological examinations at admission showed no sensorimotor deficits, no cranial nerve deficits, normal response of his reflexes, and normal standing and walking abilities without any unstableness. Blood pressure, pulse, temperature, and laboratory findings (that is, complete blood count, liver function, renal function, and C-reactive protein) were within normal range.

Surgery was indicated and written consent was obtained. Surgery was performed under general anesthesia with our patient in a semi-sitting position. Monitoring was done with somatosensory and muscle-evoked potentials. A right-sided suboccipital craniotomy was performed. On intraoperative examination, we observed a glassy gray-black tumor that was not well demarcated from the surrounding tissue. Piecemeal tumor removal was performed by microsurgical technique using the Sonoca 300 (Söring GmBH, Quickborn, Germany).

A postoperative $\mathrm{CT}$ scan revealed a regular finding without hydrocephalus and hemorrhage. Our patient was observed in our neurosurgical intensive care unit for one night and was transferred to a general ward the following day without neurological deficiency. Postoperative MRI, which was performed 48 hours after surgery, showed no residual tumor. His postoperative course was uneventful. He received no adjuvant treatment and there has been no evidence of tumor recurrence over a period of 15 months (Fig. 2). A neurological examination at last follow-up, 15 months after surgery, revealed no neurological deficits. The preoperative nausea and headache he experienced had stopped.

On histopathological examination, hematoxylin and eosin-stained paraffin sections showed predominantly small to moderately cellular tumor growing compactly,

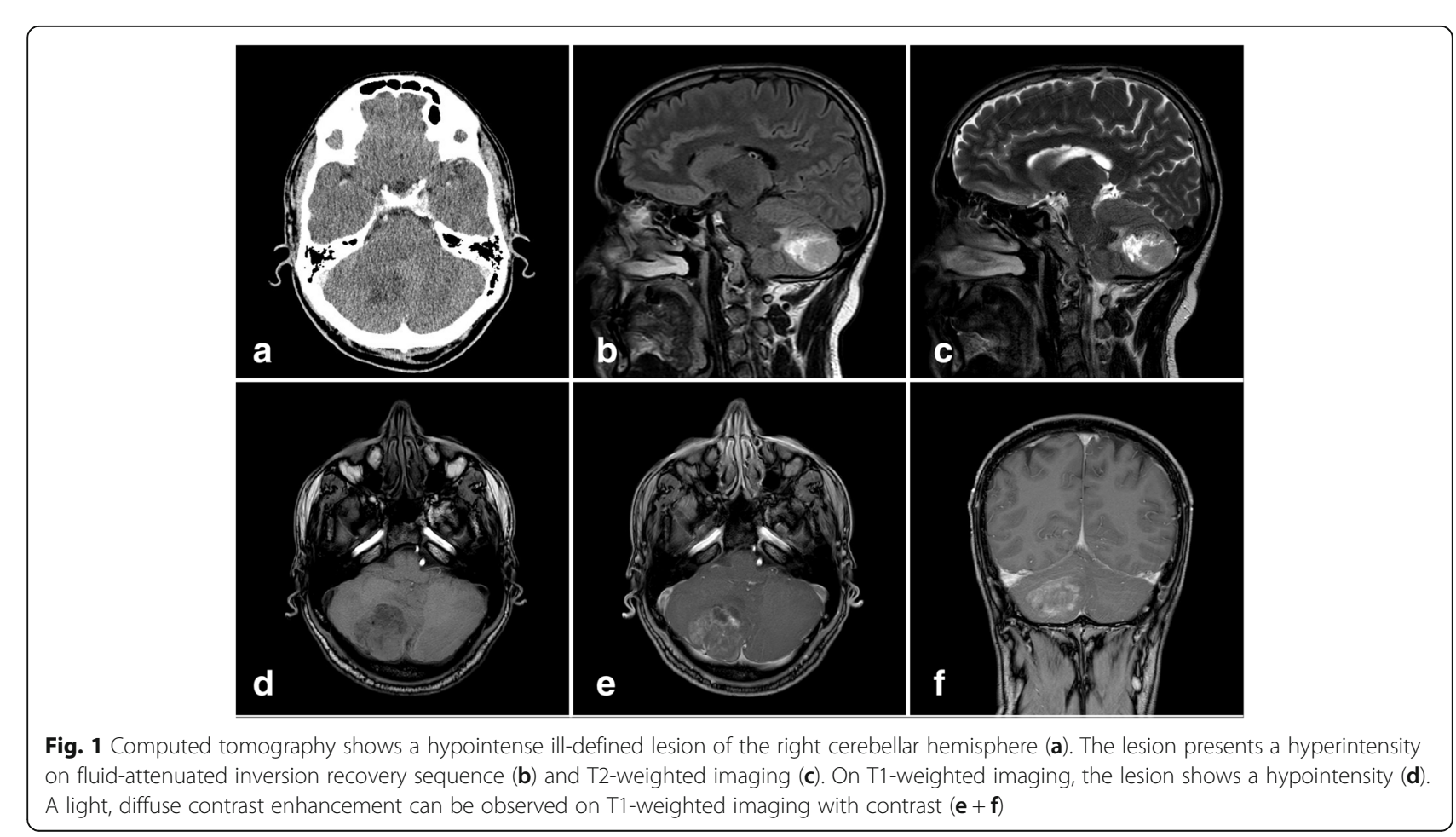



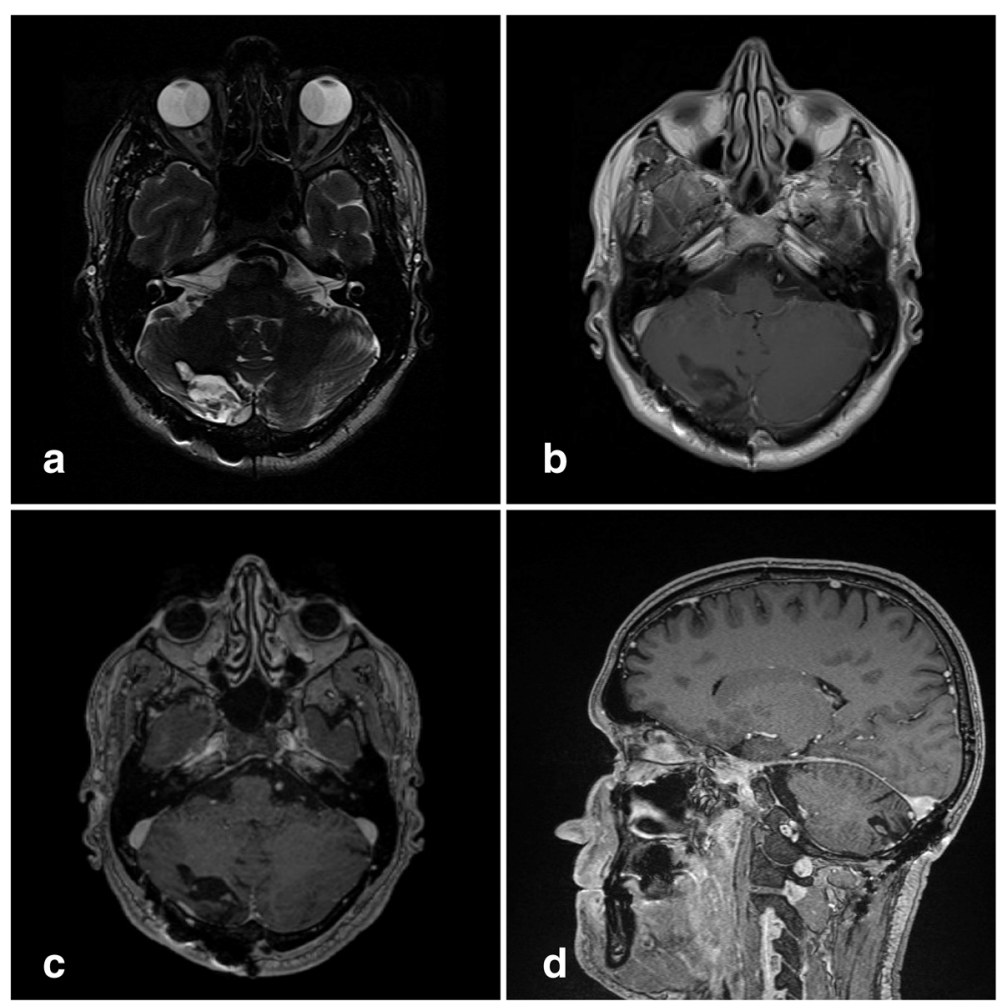

Fig. 2 Postoperative magnetic resonance imaging 15 months after surgery shows no recurrence of the tumor on T2-weighted imaging (a) and on T1-weighted imaging (b). No contrast enhancement can be seen on T1-weighted images with contrast enhancement $(\mathbf{c}+\mathbf{d})$

sometimes diffuse, infiltrating the surrounding cerebellar tissue. Tumor cells contained mainly light eosinophilic, sometimes clear, cytoplasm and round to oval nuclei and smaller nucleoli. Some tumor cells showed an astrocytic differentiation. Furthermore, around $10 \%$ of the tumor area comprised focal lipidized cells (Fig. 3a). No significant mitotic activity, $<1$ mitosis/20 high-power field (HPF), and no necrosis were observed. In immunohistochemical analysis NeuN (Fig. 3b) was detected in $80 \%$ and synaptophysin (Fig. 3c) was detected in $30 \%$ of the non-lipomatous cells. Tumor cells were negative for neurofilament (Fig. 3d; surrounding CNS tissue stained positive) and chromogranin A. Glial fibrillary acid protein (GFAP) was observed in $20 \%$ of the tumor cells (Fig. 3e). Ki-67/MIB-1 proliferation index (Fig. 3f), as determined by nuclear MIB1 monoclonal antibody staining, was around 2\% (Fig. 3).

\section{Discussion}

This case report describes an unusual case of a 39-yearold Italian man suffering from a liponeurocytoma located in the posterior fossa. Complete tumor resection was achieved and postoperative MRI revealed no residual tumor. Follow-up 15 months after surgery showed no tumor recurrence on MRI; our patient was asymptomatic. A neurological examination at follow-up revealed no neurological deficits. The radiological diagnostics, histopathological findings, differential diagnoses, and the possible adjuvant therapy are described in detail. Therefore, this case report offers an informative overview about this uncommon tumor entity.

Liponeurocytoma is a rare, benign tumor most commonly located in the posterior fossa. Mean age at the time of diagnosis is around 40 to 50 years of age. Most of the patients are more than 30 years of age. No gender predominance has been reported according to the study by Patel et al. [4]. Typically, symptoms may include headache, vomiting, nausea, and dizziness as well as ataxia with unsteadiness and frequent falls [5]. A flow obstruction of the cerebrospinal fluid may also be present [6].

Liponeurocytoma is a neurocytic neoplasm with a variable extent of neuronal/neurocytic differentiation and a focal lipomatous and astrocytic differentiation reflected by a consistent immunoreactivity to synaptophysin, neuronspecific enolase (NSE), and MAP-2. The tumor cells can also be positive for nuclear NeuN. They are negative for cytoplasmic IDH1- R132H, epithelial membrane antigen (EMA), cytokeratin (CK), and nuclear Olig-2. It shows a monotonous pattern of isomorphic round to oval cells with focal accumulations of lipid-laden cells. The 


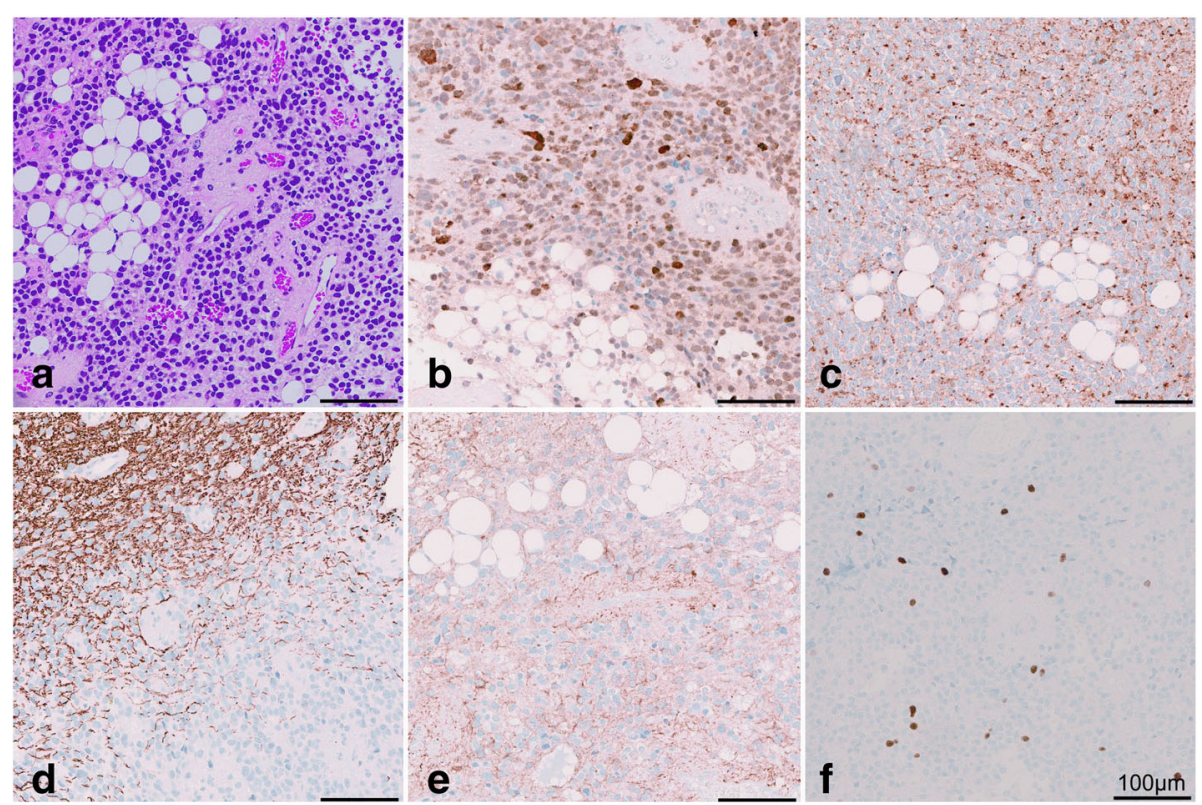

Fig. 3 Liponeurocytoma with typical histology with focal accumulation of adipocytic tumor cells; hematoxylin and eosin (a). Small tumor cells and neoplastic cells with lipomatous differentiation express NeuN (b) and synaptophysin (c). Axons of the surrounding central nervous system tissue express neurofilament (d). Expression of the astrocytic marker glial fibrillary acid protein is observed focally (e). The Ki-67 proliferation index, as determined by nuclear MIB1 monoclonal antibody staining, is low; approximately $2 \%$ (f)

lipomatous cells of the liponeurocytoma seem to be neuroepithelial tumor cells with lipid accumulation or they constitute a form of lipidization instead of true adipose cells $[7,8]$. In the lipomatous cells, the lipid vacuole membranes were positive for SYN, MAP-2, vimentin, and S-100. The expression of GFAP and S-100 is limited to scattered reactive astrocytes [9-11].

On radiological examination, liponeurocytomas often show a more or less well-demarcated hypointense mass with attenuation values of fatty tissue on $\mathrm{CT}$ scans. The tumor may be associated with parenchymal cysts or cerebellar hemorrhage [12]. MRI of a cerebellar liponeurocytoma normally shows an isointensity on T1weighted imaging, a heterogeneous intensity on T2weighted imaging, and a high intensity on diffusionweighted imaging. No or in some cases a mild surrounding edema may be observed. On FLAIR imaging a slight hyperintensity and on diffusion-weighted imaging a high intensity may be seen. A light contrast enhancement can be seen after administration of contrast agent $[13,14]$.

Differential diagnoses include oligodendrogliomas, clear cell ependymomas, or high-grade tumors like medulloblastomas. Oligodendrogliomas may show similar pathological findings demonstrating neuronal differentiation with glial and neuronal characteristics. Oligodendrogliomas show highly positive results of Olig2 immunohistochemistry [15] in contrast to liponeurocytomas [16]. Despite this, a chromosome $1 \mathrm{p} / 19 \mathrm{q}$ co-deletion is shown in $50-80 \%$ of oligodendrogliomas, while $1 \mathrm{p} / 19 \mathrm{q}$ deletion is not observed in liponeurocytomas $[17,18]$. In addition, oligodendrogliomas show a high frequency of isocitrate dehydrogenase 1 (IDH1 R132H) mutation in addition to 1p/19q co-deletion [19].

Medulloblastoma with lipidized cells and lipomatous ependymomas can be differentiated using immunohistochemical panels. Negative reaction for EMA rules out the possibility of an ependymoma. Older age of presentation (43.66 \pm 15.60 years) and extensive lipomatous change combined with a lower Ki-67/MIB-1 proliferation index favor a diagnosis of a liponeurocytoma.

Medulloblastomas show hyperdense areas with calcification in around $20 \%$ of cases on CT scans and a homogenous contrast enhancement can be observed on CT scans with contrast enhancement. On MRI, a hypointense signal on T1-weighted images and an isointense to hyperintense signal on T2-weighted images can be observed for medulloblastomas. A hyperintense FLAIR image can be detected. Diffusion-weighted images of medulloblastomas are hyperintense and on T1-weighted images with contrast enhancement medulloblastomas normally present a heterogeneous strong contrast enhancement [20].

Furthermore, Horstmann et al. analyzed the genetic profile of a liponeurocytoma [20]. They were able to show that liponeurocytoma is a distinct tumor entity that is genetically different from medulloblastomas. There was no 
case with $P T C H, A P C$, or $\beta$-catenin mutations, known to be present in subsets of medulloblastomas. Furthermore, they suggested a relationship to central neurocytomas caused by the complementary DNA (cDNA) expression array data, but the presence of TP53 mutations, which are absent in central neurocytomas, suggests that their genetic pathways are different [21].

Fluorescent in situ hybridization studies of a liponeurocytoma showed no evidence of $1 \mathrm{p} / 19 \mathrm{q}$ codeletion, $N-M Y C$ or epidermal growth factor receptor amplification, $M Y C$ or EWSR1 rearrangements, or PTEN deletion [22, 23]. In contrast to these findings, large cell/anaplastic medulloblastomas are associated with $C-M Y C$ or $N-M Y C$ amplifications [23]. Despite this, Wolf et al. [24] and Pikis et al. [16] suggested an inheritable predisposition for tumor development.

The absence of mitoses, necrosis, vascular hyperplasia, and nucleo-cytoplasmic atypia, and the low proliferation rate (MIB- $1<6 \%$ ) favor the interpretation of a benign lesion. But, Cacciola et al. showed in their review of the literature a recurrence in 20 to $32 \%$ of patients at a mean time of 10 years after surgery [25]. Interestingly, patients treated by surgery alone showed a recurrence rate of 50\% [25]. Châtillon et al. reported a recurrence rate of $50 \%$ in patients treated by subtotal resection without adjuvant radiotherapy [26]. These findings are in line with those from Limaiem et al., who were able to show mean time until recurrence of around 8.5 years [27]. In addition, they suggested that the tumor may recur due to mitoses present in the lesion and $>10 \% \mathrm{Ki}-$ 67 positive cells [27]. Radke et al. were able to show an increase of Ki-67 positive cells in recurrent tumors [23]. Due to the potentially long-term malignancy, close follow-up is recommended over that period [27, 28].

Surgery is the primary treatment of choice, but the following postoperative treatment strategy is still controversial and under discussion due to the benign character of the tumor. Long-term follow-up examinations showed a tumor recurrence in 20 to $32 \%$ of the patients at a mean time of 8 to 10 years after surgery. In addition, recurrent tumor growth is more common in patients where total resection was not achieved. Therefore, additional radiotherapy has to be discussed in those patients $[25,27]$. Jackson et al. showed in their review of the literature that a recurrence was not observed in those patients who received adjuvant radiotherapy [29]. In contrast to this, $50 \%$ of the patients who did not receive an adjuvant therapy suffered from a tumor recurrence [29]. Therefore, adjuvant therapy seems to have a favorable impact on tumor recurrence.

In summary, the present study reported a case of cerebellar liponeurocytoma that was successfully treated by total resection without tumor recurrence 15 months after surgery.

\section{Conclusions}

Liponeurocytomas are rare benign tumors occurring mainly in the cerebellum. They show a different genetic pathway compared to central neurocytomas and medulloblastomas. Surgery is the primary therapy of choice. Adjuvant radiotherapy seems to be sufficient to avoid a tumor recurrence.

\section{Abbreviations}

CNS: Central nervous system; CT: Computed tomography; EMA: Epithelial membrane antigen; FLAIR: Fluid-attenuated inversion recovery; GFAP: Glial fibrillary acid protein; MRI: Magnetic resonance imaging; WHO: World Health Organization

\section{Acknowledgements \\ We acknowledge support by the Open Access Publication Fund of the University of Duisburg-Essen.}

\section{Funding}

This research did not receive any specific grant from funding agencies in the public, commercial, or not-for-profit sectors.

\section{Availability of data and materials}

All data generated or analyzed during this study are included in this published article.

\section{Authors' contributions}

OG: Conception and design of the study; analysis and interpretation of data; drafting the article; revision and final approval of the version to be submitted. AJ: Histopathological analysis and interpretation of data; drafting the article, revision and final approval of the version to be submitted. YA: Conception and design of the study; analysis and interpretation of data; revision and final approval of the version to be submitted. US: Conception and design of the study; analysis and interpretation of data; revision and final approval of the version to be submitted. EL: Conception and design of the study; surgical performance, analysis and interpretation of data; revision and final approval of the version to be submitted. All authors read and approved the final manuscript.

\section{Ethics approval and consent to participate}

Ethical approval was not applicable for the case report. Written consent was obtained from the patient to participate in this case report.

\section{Consent for publication}

Written informed consent was obtained from the patient for publication of this case report and any accompanying images. A copy of the written consent is available for review by the Editor-in-Chief of this journal.

\section{Competing interests}

The authors declare that they have no competing interests.

\section{Publisher's Note}

Springer Nature remains neutral with regard to jurisdictional claims in published maps and institutional affiliations.

\section{Author details}

'Department of Neurosurgery, University Hospital Essen, University of Duisburg-Essen, Hufelandstrasse 55, 45122 Essen, Germany. ${ }^{2}$ Department of Neuropathology, University Hospital Essen, University of Duisburg-Essen, Essen, Germany.

Received: 3 April 2018 Accepted: 1 May 2018

Published online: 17 June 2018

\section{References}

1. Bechtel JT, Patton JM, Takei Y. Mixed mesenchymal and neuroectodermal tumor of the cerebellum. Acta Neuropathol. 1978:41:261-3.

2. Radner H, Blumcke I, Reifenberger G, Wiestler OD. The new WHO classification of tumors of the nervous system 2000. Pathology and genetics. Pathologe. 2002;23:260-83. 
3. Louis DN, Perry A, Reifenberger G, von Deimling A, Figarella-Branger D, Cavenee WK, Ohgaki H, Wiestler OD, Kleihues P, Ellison DW. The 2016 World Health Organization Classification of Tumors of the Central Nervous System: a summary. Acta Neuropathol. 2016;131:803-20.

4. Patel N, Fallah A, Provias J, Jha NK. Cerebellar liponeurocytoma. Can J Surg. 2009:52:E117-9.

5. Chakraborti S, Mahadevan A, Govindan A, Yasha TC, Santosh V, Kovoor JM, Ramamurthi R, Alapatt JP, Hedge T, Shankar SK. Supratentorial and cerebellar liponeurocytomas: report of four cases with review of literature. J Neuro-Oncol. 2011;103:121-7.

6. Gupta K, Salunke P, Kalra I, Vasishta RK. Central liponeurocytoma: case report and review of literature. Clin Neuropathol. 2011;30:80-5.

7. $\mathrm{Xu} \mathrm{L,} \mathrm{Du} \mathrm{J,} \mathrm{Wang} \mathrm{J,} \mathrm{Fang} \mathrm{J,} \mathrm{Liu} \mathrm{Z,} \mathrm{He} \mathrm{Y,} \mathrm{Li} \mathrm{G.} \mathrm{The} \mathrm{clinicopathological} \mathrm{features}$ of liponeurocytoma. Brain Tumor Pathol. 2017;34:28-35.

8. Louis DN, Ohgaki H, Wiestler OD, Cavenee WK, Burger PC, Jouvet A, Scheithauer BW, Kleihues P. The 2007 WHO classification of tumours of the central nervous system. Acta Neuropathol. 2007;114:97-109.

9. Rajesh L, Jindal A, Banjerjee A. Liponeurocytoma of lateral ventricle. Neurol India. 2010;58:805-6.

10. Jouvet A, Lellouch-Tubiana A, Boddaert N, Zerah M, Champier J, FèvreMontange M. Fourth ventricle neurocytoma with lipomatous and ependymal differentiation: a case report. Acta Neuropathol. 2005;109: 346-51.

11. George D, Scheithauer B. Central Liponeurocytoma: Case Report. A J Surg Pathol. 2001;25:1551-5

12. Kuchelmeister K, Nestler U, Siekmann R, Schachenmayr W. Liponeurocytoma of the left lateral ventricle-case report and review of the literature. Clin Neuropathol. 2006;25:86-94.

13. Takami H, Mukasa A, Ikemura M, Shibahara J, Takahashi M, Momose T, Saito N. Findings from positron emission tomography and genetic analyses for cerebellar liponeurocytoma. Brain Tumor Pathol. 2015;32:210-5.

14. Beizig N, Ziadi S, Ladib M, Mokni M. Cerebellar liponeurocytoma: case report. Neurochirurgie. 2013;59:39-42.

15. Marie Y, Sanson M, Mokhtari K, Leuraud P, Kujas M, Delattre JY, Poirier J, Zalc B, Hoang-Xuan K. OLIG2 as a specific marker of oligodendroglial tumour cells. Lancet. 2001;358:298-300.

16. Pikis S, Fellig Y, Margolin E. Cerebellar liponeurocytoma in two siblings suggests a possible familial predisposition. J Clin Neurosci. 2016;32:154-6.

17. Reifenberger G, Louis DN. Oligodendroglioma: toward molecular definitions in diagnostic neuro-oncology. J Neuropathol Exp Neurol. 2003;62:111-26

18. Weller M, Stupp R, Hegi ME, van den Bent M, Tonn JC, Sanson M, Wick W, Reifenberger G. Personalized care in neurooncology coming of age: why we need MGMT and $1 \mathrm{p} / 19 \mathrm{q}$ testing for malignant glioma patients in clinical practice. Neuro-Oncology. 2012;14(Suppl 4):iv100-8.

19. Labussiere MIA, Wang X-W, Marie Y, Boisselier B, Falet C, Paris S, Laffaire J, Carpentier C, Criniere E. All the 1p19q codeleted gliomas are mutated on IDH1 or IDH2. Neurology. 2010;74:1886-90.

20. Koeller KK, Rushing EJ. From the archives of the AFIP: medulloblastoma: a comprehensive review with radiologic-pathologic correlation. Radiographics. 2003;23:1613-37.

21. Horstmann S, Perry A, Reifenberger G, Giangaspero F, Huang H, Hara A, Masuoka J, Rainov NG, Bergmann M, Heppner FL, et al. Genetic and expression profiles of cerebellar liponeurocytomas. Brain Pathol. 2004;14: 281-9.

22. Tucker A, Boon-Unge K, McLaughlin N, Ibrahim H, Rao N, Martin N, Everson R, Khanlou N. Cerebellar Liponeurocytoma: Relevant Clinical Cytogenetic Findings. J Pathol Transl Med. 2017;51:335-40.

23. Radke J, Gehlhaar C, Lenze D, Capper D, Bock A, Heppner FL, Jodicke A, Koch A. The evolution of the anaplastic cerebellar liponeurocytoma: case report and review of the literature. Clin Neuropathol. 2015;34:19-25.

24. Wolf A, Alghefari H, Krivosheya D, Staudt MD, Bowden G, Macdonald DR, Goobie S, Ramsay D, Hebb MO. Cerebellar liponeurocytoma: a rare intracranial tumor with possible familial predisposition. Case report. J Neurosurg. 2016;125:57-61.

25. Cacciola F, Conti R, Taddei GL, Buccoliero AM, Di Lorenzo N. Cerebellar liponeurocytoma. Case report with considerations on prognosis and management. Acta Neurochir. 2002;144:829-33.

26. Châtillon CE, Guiot MC, Roberge D, Leblanc R. Cerebellar liponeurocytoma with high proliferation index: treatment options. Can J Neurol Sci. 2009;36: 658-61.
27. Limaiem F, Bellil S, Chelly I, Bellil K, Mekni A, Jemel H, Haouet S, Zitouna M, Kchir N. Recurrent cerebellar liponeurocytoma with supratentorial extension Can J Neurol Sci. 2009;36:662-5.

28. Aker F, Ozkara S, Eren P, Peker O, Armağan S, Hakan T. Cerebellar liponeurocytoma/lipodized medulloblastoma. J Neuro-Oncol. 2005;71:53-9.

29. Jackson TR, Regine WF, Wilson D, Davis DG. Cerebellar liponeurocytoma. Case report and review of the literature. J Neurosurg. 2001;95:700-3.

\section{Ready to submit your research? Choose BMC and benefit from:}

- fast, convenient online submission

- thorough peer review by experienced researchers in your field

- rapid publication on acceptance

- support for research data, including large and complex data types

- gold Open Access which fosters wider collaboration and increased citations

- maximum visibility for your research: over $100 \mathrm{M}$ website views per year

At BMC, research is always in progress.

Learn more biomedcentral.com/submissions 